\begin{tabular}{|l|l|l||}
\hline \multicolumn{2}{|c|}{ PublisherInfo } \\
\hline \hline PublisherName & $:$ & BioMed Central \\
\hline \hline PublisherLocation & $:$ & London \\
\hline \hline PublisherImprintName & $:$ & BioMed Central \\
\hline \hline
\end{tabular}

\title{
Does endotracheal administration of adrenaline (epinephrine)
} work?

\begin{tabular}{|l|l|l||}
\hline \multicolumn{2}{|c||}{ ArticleInfo } \\
\hline \hline ArticleID & $:$ & 4209 \\
\hline \hline ArticleDOI & $:$ & $10.1186 /$ ccf-2000-5458 \\
\hline \hline ArticleCitationID & $:$ & 5458 \\
\hline \hline ArticleSequenceNumber & $:$ & 68 \\
\hline \hline ArticleCategory & $:$ & Paper Report \\
\hline \hline ArticleFirstPage & $:$ & 1 \\
\hline \hline ArticleLastPage & $:$ & 4 \\
\hline \hline & $:$ & RegistrationDate : 2000-6-15 \\
\hline ArticleHistory & $:$ & OnlineDate \\
\hline \hline ArticleCopyright & $:$ & Current Science Ltd2000-6-15 \\
\hline \hline ArticleGrants & $:$ & \\
\hline \hline ArticleContext & $:$ & 1305422 \\
\hline \hline
\end{tabular}


Aff1 The Royal Melbourne Hospital, Australia

\section{Keywords}

Adrenaline, endotracheal administration

\section{Comments}

Most international guidelines, including those from ILCOR1 (International Liaison Committee on Resuscitation), recommend endotracheal administration of adrenaline in cardiac arrest, when an intravenous (IV) route is not available. This is based on work done on animals and on single observations in humans, particularly neonates. Recently there has been controversy over this, with investigators claiming that adrenaline administered via an endotracheal tube (ET) does not work (see additional comments below).This study addresses the issue of average dosing requirements and compares the efficacy of the two routes (IV vs ET). The results suggest that there is a role for ET administration of adrenaline; however, it appears that there is a significant time lag following ET administration. The average doses used in this study, although within the limits as prescribed by the guidelines, are higher than in the previous studies. It is important to bear in mind that the individuals in the study were hypotensive, but were not in a cardiac arrest situation. This is a small non-randomized study and provides only circumstantial evidence that ET administration of adrenaline works.

\section{Introduction}

To assess the efficacy of endotracheal administration of adrenaline (epinephrine) in humans.

\section{Methods}

- Prospective randomized trial involving 34 anesthetized patients (5 women, 29 men) receiving an implantable cardio-verter defibrillator. 
- After intubation, when mean arterial pressure (MAP) fell below $80 \mathrm{mmHg}$ (after adequate fluid loading), IV adrenaline was injected via central line, at a dose of $1 \mu \mathrm{g} / \mathrm{kg}$, with dose escalation to achieve the required MAP.

- Once the IV dose was established, the next time they were hypotensive, 100 times the IV dose was administered diluted in $10 \mathrm{ml}$ of saline and administered slowly over 5 seconds into the airways, followed by 10 forced ventilations.

- There were two subgroups: one group received adrenaline directly into the ET $(\mathrm{n}=17)$, and the other received adrenaline via a bronchial catheter wedged into a bronchus (laced under radiological guidance) $(\mathrm{n}=17)$.

- The patients' clinical characteristics apparently did not differ between groups (data not shown).

- Mean dose of adrenaline $\pm \mathrm{SD}=1.3 \pm 0.6 \mathrm{mg}$ (range, 0.7 to $3 \mu \mathrm{g}$ )

- Plasma catecholamine samples were collected from the second lumen of the central intravenous line immediately before adrenaline administration; $0.5,2,3$, and 5 min after IV administration; and $0.5,2,3,5,10$, and 20 min after ET administration.

\section{Results}

Airway administration of adrenaline significantly increased plasma adrenaline levels more than 200-fold, from $0.26 \pm 0.21 \mathrm{nmol} / 1$ (range, 0.05 to $0.71 \mathrm{nmol} / 1$ ) to $57.9 \pm 56.8 \mathrm{nmol} / 1$ (range, 8.2 to 205.8 $\mathrm{nmol} / \mathrm{l})(P=0.0015)$. MAP increased by almost $100 \%(P<0.001)$, and heart rate increased from $64.0 \pm$ 12.6 beats $/ \mathrm{min}$ (range, 40 to 100 beats $/ \mathrm{min}$ ) to a maximum of $79.7 \pm 20.5$ beats $/ \mathrm{min}$ (range, $50-140$ beats $/ \mathrm{min}$ ). A delayed response was seen when adrenaline was administered through the airways. Mean time to first response in MAP of $>10 \mathrm{mmHg}$, via the IV route, was $25.1 \pm 15.1$ seconds (SD 3.6-79.2) and via the ET route $64.0 \pm 68.5$ seconds (SD 8.4-279.6), $P<0.001$. Mean time to reach the peak effect on MAP in seconds via IV route was $82.3 \pm 31.0$ (SD 11-131) and via the ET route was $219.8 \pm 136.2$ (SD 62-528), $P<0.001$. There was no statistical difference between the two airway subgroups. ET administration of adrenaline appears as effective as IV; however, a time lag was seen and peripheral bronchial administration of adrenaline through a catheter (which is cumbersome and time-consuming) seems unnecessary.

\section{Additional information}

1. The universal advanced life support algorithm: an advisory statement from the Advanced Life Support Working Group of the International Liaison Committee on Resuscitation. (Kloeck W et al, Circulation 1997, 95:2180-2182) 
2. Endotracheal versus intravenous epinephrine during electromechanical dissociation with CPR in dogs. (Ralston et al, Ann Emerg Med 1985, 14:1044-1048).

3. Comparison of endotracheal and peripheral intravenous adrenaline in cardiac arrest. Is the endotracheal route reliable? (Quinton et al, Lancet 1987, 1:828-829.

4. Haemodynamic effects of tracheal compared with intravenous adrenaline (McCrirrick et al, Lancet 1992, 340:868-870.

5. Comparison of i.v. and intra-tracheal administration of adrenaline (McCrirrick et al, Br J Anaesth 1994, 72:529-532)

\section{References}

1. Raymondos K, Panning B, Leuwer M, Brechelt G, Korte T, Niehaus M, Tebbenjohanns J, Piepenbrock S: Absorption and hemodynamic effects of airway administration of adrenaline in patients with severe cardiac disease. Ann Intern Med. 2000, 132: 800-803. 